\title{
Gestão estratégica dos custos invisíveis: o caso das empresas estatais transmissoras de energia elétrica do Brasil
}

\begin{abstract}
Marcelo Dutra
Mestrado em Contabilidade pela Universidade Federal de Santa Catarina - UFSC Av. Prof. Luciano Gualberto, trav. 3. Prédio da Eng. Elétrica. LARC. São Paulo/SP. CEP: 05508-900 E-mail:mhdutra@eletrosul.gov.br

Antônio Cezar Bornia Doutorado em Engenharia de Produção pela Universidade Federal de Santa Catarina UFSC Professor da Universidade Federal de Santa Catarina - UFSC Campus Universitário Trindade. CP 476. Florianópolis/SC. CEP: 88040-900 E-mail: cezar@inf.ufsc.br
\end{abstract}

\section{RESUMO}

O presente artigo tem como objetivo apresentar a gestão estratégica dos custos invisíveis, focada na maximização de resultados, em empresas estatais transmissoras de energia elétrica do Brasil. Para atingir o objetivo proposto, apresenta-se inicialmente um estudo de caso realizado com a empresa Eletrosul, desenvolvido por intermédio de fontes documentais e da aplicação de entrevistas não estruturadas. Em seguida, através de raciocínio indutivo (do específico para o geral), após a exposição do case (específico), é arquitetado um constructo teórico, com base em duas assertivas fundamentadas, em que se propõe a gestão estratégica dos custos invisíveis como uma possível alternativa para as empresas estatais transmissoras de energia (geral), levando em conta suas características de ineficiência na gestão econômica e, em contra-senso, a eminente necessidade de maximização dos resultados.

Palavras-chave: Gestão Estratégica de Custos. Custos Invisíveis. Setor Elétrico. Transmissoras Estatais. Eletrosul.

\section{Strategic invisible costs management: the case of the public companies that transmit electric energy in Brasil}

\section{ABSTRACT}

This job has as its goal to introduce the strategic invisible costs management for to maximize the results of the public companies that transmit electric energy in Brazil. To reach the proposed goal, one case study with the Eletrosul company is presented, accomplished by documents and by interviews non-structured. Through the inductive 
method (of the specific for the general), after the exhibition of the case (the specific), is built-up a base theoretical with fundament in two premises theoretical-empirical. This framework has as objective to proposed the strategic invisible costs management as a possible option for the companies that transmit electric energy (the general). This, in function of the no-efficiency financial administration, and of the need to maximize economic results of these companies.

Key Words: Strategic Costs Management. Invisible Costs. Electrical Sector. Public Companies that Transmit Electric Energy. Eletrosul.

\section{INTRODUÇÃO}

Em mercados comoditários o ambiente competitivo trazido, principalmente, pela globalização faz com que as empresas busquem soluções eficientes para seus problemas, sobretudo no que diz respeito à gestão de custos. Neste nicho empresarial, aos grandes líderes é imposto o desafio de estudar a sua empresa, o ambiente em que ela se insere e os processos produtivos envolvidos na consecução de suas atividades, na busca incessante de processos que não agregam os valores esperados, para a redução ótima de seus gastos. A redução ótima é encontrada no equilíbrio e no respeito às proporções das despesas e investimentos, de maneira a permitir a manutenção da atividade empresarial em níveis aceitáveis e desejáveis.

Reduzir de maneira desenfreada os gastos sem que se avaliem as variáveis intrínsecas e os riscos que podem acarretar tais decisões não é recomendável. É preciso analisar cuidadosamente cada uma das atividades integrantes dos processos empresariais a fim de encontrar alternativas para atenuar os fatores ocultos que geram gastos desnecessários, os quais, por suas características e peculiaridades, não são mensurados e nem apresentados pelos sistemas tradicionais de custos (HAMMOND; KEENEY; RAIFA, 2006).

Há que se notar que por trás de toda organização empresarial existe uma estrutura corporativa que envolve questões complexas, principalmente relacionadas ao comportamento das pessoas. Disso resulta, em alguns casos, negócios aparentemente viáveis, com margens de contribuições magníficas na fase de planejamento, mas que acabam gerando, ao final do empreendimento, prejuízo econômico e financeiro nas 
operações. Muitas vezes, a má gestão dos designados custos invisíveis é que origina situações indesejadas desta natureza (FALCONER; WHITBY, 1999).

Em linhas gerais, os custos invisíveis são encontrados em empresas que têm como característica fundamental a ineficiência na gestão dos recursos disponíveis, dentre as quais podem ser destacadas as empresas estatais brasileiras transmissoras de energia elétrica (ou simplesmente transmissoras estatais). Não obstante à questão da ineficiência, estas empresas passam, atualmente, por uma complexa e contraditória situação: precisam maximizar seus resultados para manter a competitividade em um mercado em que os novos investimentos são determinados por meio de leilões, ao mesmo tempo em que possuem limitações resultantes de um modelo burocrático de controle imposto pelo governo, que culmina no engessamento de sua gestão, levandoas a resultados econômicos de pouca expressão em relação à sua capacidade de gerar lucro.

Nesse contexto surge o seguinte problema: como a gestão estratégica dos custos invisíveis pode contribuir para a maximização dos resultados das empresas estatais brasileiras transmissoras de energia elétrica?

No intuito de responder ao questionamento, o presente artigo está organizado da seguinte maneira: na seção que segue elabora-se uma revisão de literatura acerca dos custos invisíveis; na seqüência descreve-se o delineamento do trabalho; em seguida, aborda-se o estudo de caso; ato contínuo se apresenta o constructo teórico desenvolvido; e, para findar, na seção 6 são tecidas as considerações finais.

A relevância da discussão sobre o tema proposto pode ser expressa pelo próprio entendimento da agência que regulamenta o setor elétrico, a ANEEL (2008), a qual projeta como uma das principais oportunidades de negócio no segmento a construção de linhas de transmissão, em função da atual realidade do mercado de energia brasileiro, mas que, por outro lado, considera a carência de aporte de recursos como o principal obstáculo limitador para que esses investimentos sejam realizados pelo poder público, através de suas estatais. 
Gestão estratégica dos custos invisíveis: o caso das empresas estatais transmissoras de energia elétrica do Brasil Marcelo Dutra, Antônio Cezar Bornia

\section{OS CUSTOS INVISÍVEIS}

O tema relacionado à identificação e gestão de fatores ocultos que geram gastos que podem ser evitados, tem como referência o trabalho apresentado por Miller e Vollmann (1985). Nesse estudo, os autores destacaram a importância de se levar em consideração na gestão das organizações os fatores que podem gerar os designados custos invisíveis, antecipadamente aos seus efeitos.

Desde que foi publicado o referido trabalho acadêmico, outras pesquisas foram divulgadas relativamente ao tema, todavia, os pesquisadores que trataram do assunto 0 fizeram abordando-o de uma maneira predominantemente pragmática. Embora haja de fato uma relativa incipiência no tratamento do assunto em termos acadêmico, já é possível de se verificar que, na prática empresarial, a busca pela melhora da performance econômica das empresas tem dado ênfase à discussão da eliminação de gastos desnecessários, normalmente intitulando-os de uma maneira genérica como desperdício de recursos.

Embora a concepção de custos invisíveis seja distinta do conceito de desperdício, do ponto de vista teórico não existe, ainda, consolidado, nenhum conceito sobre o tema. Todavia, há que se verificar que o desperdício ocorre quando o fato já está concretizado, ou seja, já se tem caracterizada uma perda, muito embora esta possa ainda ser revertida (só há desperdício do que se tem). A concepção adotada sob a ótica dos custos invisíveis remete a, pelo menos, uma etapa antes dos desperdícios, de tal modo que só irá existir tal perda se for falha a gestão do fator identificado como desencadeador de "custos invisíveis".

Assim sendo, os custos invisíveis são aqueles de difícil identificação e mensuração, motivados por processos burocráticos e ineficientes. Não se configuram especificamente como gastos contábeis, mas poderão resultar em um (gasto - passivo de contabilização), no futuro, caso não sejam preventivamente tratados; tendo em vista que podem ser evitados. Atente-se também ao fato de que, normalmente, quando se tornam um gasto, do ponto de vista contábil, acabam sendo qualificados com outras 
terminologias que não as que efetivamente Ihes originaram; os verdadeiros fatores que Ihes deram origem (FALCONER; WHITBY, 1999).

Portanto, esses custos são originados a partir de fatores ocultos mal-gerenciados e é, justamente, em virtude da má gestão desses fatores que se permite a sua geração, embora eles somente sejam reconhecidos na contabilidade quando se tornarem passíveis de mensuração e no momento em que forem contabilmente reconhecidos como um gasto.

De acordo com Rosa (2004), os custos invisíveis podem ser classificados como "não-contábeis", levando em consideração que estes, geralmente, não são apresentados nos demonstrativos contábeis tradicionais. Sobre este aspecto, necessário é refletir que a classificação como "não-contábeis" não implica em afirmar que os efeitos destes custos nunca passarão a compor o resultado contábil. Observe-se que tais custos irão, sim, aparecer na contabilidade da entidade quando se tornarem irreversivelmente um gasto, deixando de serem supostamente "invisíveis" para se tornarem, conseqüentemente, "visíveis" ao patrimônio da entidade. Em outras palavras, em razão da falta de controle e ação sobre determinadas situações e fatores, os efeitos negativos tornam-se não mais evitáveis quando os custos invisíveis forem contabilmente passíveis de reconhecimento.

Verifique-se, destarte, que no conceito de custos invisíveis a terminologia "custos" difere daquela que é a utilizada tradicionalmente pela ciência contábil, a qual trata custos como gastos destinados ao investimento (um Ativo). A abordagem ao conceito referido remete a discussão do assunto à ótica gerencial dos custos, não tendo como foco a questão relativa aos conceitos adotados pela ciência contábil, que diferencia os termos gastos e custos, ambos já assumidos economicamente pela entidade. Assim, sob o olhar contábil, custos invisíveis não existem, pois, em tese, não existe ainda um fato gerador do gasto. Contudo, sob o olhar gerencial o fato gerador deve ser verificado antes de ocorrido economicamente, tendo em vista que é só desta forma (antecipando-se a sua ocorrência), que se pode adotar medidas para evitá-los ou, pelo menos, atenuá-los. 
Gestão estratégica dos custos invisíveis: o caso das empresas estatais transmissoras de energia elétrica do Brasil

Marcelo Dutra, Antônio Cezar Bornia

Nesse sentido, Bernardi (2004) explicita que os custos invisíveis começam quando há falta ou desbalanceamento de fatores essenciais de uma gestão de qualidade. Dentre os principais, o autor elenca: Visão, que pode gerar confusão nas organizações; Cultura, que pode gerar resistências; Estrutura, que pode gerar ansiedade; Recursos, que pode gerar frustração; Estratégia, que pode gerar múltiplos obstáculos. Sobre esses fatores, Bernardi (2004, p. 265) pondera que

há um elenco de situações, possibilidades e comportamentos orbitando em torno dos cinco fatores, que geram custos invisíveis: falta de integração, desarmonias, modismos, politicagem, clima, boicotes, desconfiança, controles excessivos, desmotivação, poluição de informações, liderança ausente, desconfiança, gorduras estruturais, sistemas e tecnologias obsoletas, retrabalho, baixa produtividade, urgências, acomodação, mau uso de recursos, etc.

Segundo Zaffani (2006), para melhor compreender os custos invisíveis pode-se agrupá-los em seis diferentes campos, de acordo com os fatores que os originam, sendo eles:

- Relações Humanas - clima organizacional ruim, gerado, entre outras, pela permissividade em relação aos boatos, fofocas e politicagem interna. Aceitação natural de críticas destrutivas, boicotes e resistências. Sistemas de comunicação ineficientes que alimentam mal-entendidos e inviabilizam a harmonia interna. Não saber aproveitar e direcionar adequadamente os talentos internos. Inexistência ou falta de diálogo. Falta de sintonia entre as pessoas. Falta de autenticidade, falsidade e desgaste inter-pessoal. Apatia e isolamento das pessoas;

- Controles - criação de controles internos em excesso. Excesso de informação e de dados desnecessários, que não agregam valor. Inexistência ou falta de controles apropriados. Falta de organização. Excesso de burocracia;

- Pessoal - falta de motivação e de interesse. Inexistência de cooperação entre 
as pessoas. Competição predatória. Bloqueio do aprendizado, gerado pela prepotência e arrogância das pessoas. Desmotivação e postura alheia à resolução de problemas (do tipo: "não é problema meu!"). Inexistência ou falta de criatividade;

- Recursos Materiais - ociosidade dos ativos. Mau uso dos bens e instalações. Utilização de tecnologias ultrapassadas e obsoletas. Conveniência e manutenção de estoques mínimos de segurança acima do razoável. Falta de manutenção ou manutenção excessiva. Aceitação de estruturas superdimensionadas;

- Gestão - utilização de sistemas e processos obsoletos. Falta de austeridade no trato das questões que se relacionam à empresa. Falta de planejamento. Planejamento focado apenas no curto prazo. Falta de lideranças naturais. Lideranças omissas e ausentes. Execução de trabalhos em duplicidade. Morosidade no processo decisório. Decisões baseadas em análises superficiais. Negociações mal conduzidas e com baixo nível de compromisso e exigências. Incoerência nas decisões entre produzir internamente ou terceirizar. Manter procedimentos e tomar decisões baseadas na memória institucional (do tipo: "foi assim que nós crescemos! "; "isso sempre deu certo!");

- Treinamento/Qualidade - falta de preparo que gera o refazer, corrigir e/ou compensar os erros e falhas. Falta de controle dos desperdícios e dos itens não produtivos. Qualidade a qualquer preço. Falta de reciclagem de materiais. Falta de profissionalismo. Funcionários desempenhando atribuições para as quais não foram adequadamente preparados. Fazer e refazer o que não é mais necessário. Atender pedidos urgentes, sem o devido planejamento.

Zaffani (2006) destaca, ainda, que as causas mais comuns que conduzem as empresas a ignorarem esses fatores são:

- Gerenciamento permissivo e tolerante com ocorrências que embutem custos 
Gestão estratégica dos custos invisíveis: o caso das empresas estatais transmissoras de energia elétrica do Brasil

Marcelo Dutra, Antônio Cezar Bornia

não valorados e, com isso, incentiva-se o desenvolvimento de condutas e atitudes que, além de não agregarem valor, contribuem para um ambiente interno negativo, sem comprometimento, cooperação e profissionalismo;

- Cultura interna construída com base em valores discutíveis do ponto de vista ético, moral e comportamental;

- Lucros expressivos no passado ou no presente, que podem desenvolver um nível inaceitável de tolerância e acomodação;

- Protecionismo, que dificulta a implantação de uma gestão profissional;

- Estruturas de pessoal construídas há muitos anos e em bases que não mais se sustentam diante dos desafios atuais;

- Preparação, treinamento e atualização profissional insuficientes.

Para Peter Drucker (apud SCHLENDER, 2004), a relevância dos custos invisíveis se tornou tal que, em muitas companhias, eles têm se tornado mais significativos do que os próprios custos da mão-de-obra direta. Dessa forma, deve-se considerar a gestão sobre os custos invisíveis, em detrimento de uma gestão centrada somente em torno dos dados concretos, visíveis, quantificáveis e reportáveis nos demonstrativos e sistemas de informações tradicionais de custos.

Ao contrário de grande parte das ferramentas de gestão, geralmente voltadas a aspectos explícitos e concretos, a gestão estratégica dos custos invisíveis tende a observar custos implícitos gerados pelo contexto ambiental e organizacional, independente de serem ou não mensurados, que corroem os fundamentos e as sustentações básicas de rentabilidade, lucratividade e sustentabilidade (BERNARDI, 2003).

\section{DELINEAMENTO DO TRABALHO}

\subsection{Origem, motivação e método da pesquisa}

Este trabalho originou-se a partir de outro estudo que foi desenhado para identificar, em empresas do segmento de energia elétrica, os fatores mais expressivos que geram custos invisíveis. No decorrer do referido estudo, ainda não concluído, 
verificou-se, por meio de questionários, que as empresas transmissoras de energia, mais especificamente as estatais consideradas no estudo, apresentavam, sem exceção, um mesmo fator preponderante, que poderia desencadear futuros gastos relevantes para a empresa.

Ao observar tal fato, os pesquisadores envolvidos naquele estudo resolveram aprofundar-se, em pesquisa à parte, no problema que se manifestava, ainda que, na maioria das empresas investigadas, de maneira incipiente. As respostas obtidas com a aplicação do referido questionário apresentavam-se, apenas no caso da empresa Eletrosul, com um direcionamento para uma possível resolução do problema. Foi esta a única empresa que relatou procedimentos de gestão para gerenciar o referido fator de custo invisível verificado. Desta forma, optou-se por um aprofundamento do estudo do fator gerador de custos invisíveis, identificado unanimemente como prevalecente, a partir do caso reportado por esta empresa. A opção pela empresa em estudo não foi uma deliberação livre dos pesquisadores, portanto, mas sim, deu-se em função do resultado do estudo anterior.

Não obstante, é resultante de tal contexto este artigo, cujo objetivo é o de apresentar a gestão estratégica dos custos invisíveis, focada na maximização de resultados, em empresas estatais transmissoras de energia elétrica do Brasil. Para tanto, apresenta-se inicialmente o caso Eletrosul. Em seguida, a partir das evidências extraídas do caso, utilizando-se de uma linha de raciocínio indutiva (método científico), chega-se a uma proposta genérica para se apresentar extensivamente às demais transmissoras estatais nacionais.

A esse respeito, cabe lembrar que, segundo Gil (1995), o método indutivo baseia-se na idéia de que o conhecimento é fundamentado na experiência, não levando em conta princípios pré-estabelecidos. No raciocínio indutivo, generalizações derivam de observações de casos da realidade concreta e não do universo abstrato, e as constatações particulares é que levam à elaboração de tais generalizações, ou seja, parte-se do específico para o geral.

Quanto à legitimidade da empresa em estudo, algumas referências empíricas dão conta de se tratar de uma organização reconhecidamente experimentada e 
Gestão estratégica dos custos invisíveis: o caso das empresas estatais transmissoras de energia elétrica do Brasil

Marcelo Dutra, Antônio Cezar Bornia

consolidada no setor, de modo que não se alude a um caso utópico. Segundo Souza (1995), a Eletrosul é uma das mais eficientes dentre as empresas que exploram a atividade de transmissão de energia elétrica no Brasil, tendo contribuído significativamente para o crescimento da transmissão (e geração) de energia elétrica no sul do país, desde sua constituição, no ano de 1968. Há que se acrescentar ainda que a empresa foi escolhida, pela quarta vez consecutiva, como a melhor empresa do setor elétrico nacional; premiação concedida pela "Revista ISTOÉ Dinheiro", com base em cinco quesitos: sustentabilidade financeira, compromisso social e com o meio ambiente, inovação e qualidade, recursos humanos e governança corporativa.

\subsection{Enquadramento metodológico, procedimentos e limitação do estudo}

O enquadramento metodológico deste trabalho pode ser caracterizado, com base em Gil (1995), da seguinte maneira: quanto à natureza, como uma pesquisa aplicada, a qual tem como objetivo produzir conhecimentos para aplicação prática; quanto aos objetivos, como uma pesquisa exploratória, por tratar de um tema ainda incipiente na literatura acadêmica; quanto à abordagem do problema, como qualitativo; e, quanto aos procedimentos, como um estudo de caso, que foi desenvolvido por intermédio de fontes documentais e da aplicação de entrevistas não estruturadas (após o estudo de caso, foram, também, aplicados questionários).

A coleta de dados para o estudo do case foi realizada a partir, ordenadamente, das seguintes etapas: i) levantamento em fontes documentais representadas, resumidamente, por um único relatório final (ELETROSUL, 2005); documento este que foi o oficialmente enviado no ano de 2005 para o Ministério do Planejamento, Orçamento e Gestão, do Governo Federal; e, ii) após findadas as análises sobre esta etapa, procederam-se entrevistas não estruturadas com a parte do corpo técnico da empresa responsável pelo programa implementado para a gestão do referido fator de custos invisíveis (este programa é abordado com mais detalhes na seção do estudo de caso).

Segundo Yin (2004), as evidências extraídas de um estudo de caso são generalizáveis para proposições teóricas dentro do que se trata no próprio estudo, não 
servindo, necessariamente, como generalização para populações ou universo. Ou seja, o emprego desta técnica de pesquisa busca expandir o conhecimento específico existente acerca dos assuntos que são tratados no próprio estudo (generalização analítica aprofundada), sem a pretensão de criar novas teorias e constructos, ou mesmo de servir como modelo para generalizações científicas de amplo alcance.

Neste contexto, reconhecendo-se que o procedimento adotado neste trabalho (estudo de caso) constitui-se em uma metodologia que é limitada para a realização de generalizações, elaborou-se, com base na análise dos dados do caso Eletrosul, um questionário para a verificação de tal fator, de maneira mais aprofundada nos demais casos de empresas estatais transmissoras de energia elétrica do Brasil. Este questionário foi enviado a todas as empresas que se enquadravam nesta população. Obteve-se resposta de todos os questionários enviados, porém, exceto em um dos casos, as empresas não autorizaram a divulgação dos dados dos questionários, de maneira que não foi possível expor os resultados analiticamente, apenas de um modo generalizado.

Infelizmente, a restrição imposta para a evidenciação dos dados acaba por limitar a possibilidade de demonstrar individualmente como o referido fator de custos invisíveis apresenta-se em cada uma das empresas que compõem a população. No entanto, tanto em termos acadêmicos para futuras pesquisas, quanto em termos práticos para uso de benchmarking empresarial, acredita-se na riqueza que pode proporcionar a exposição de uma metodologia de gerenciamento que tem se demonstrado eficiente, de maneira a servir de modelo em situações similares.

A esse respeito, resumidamente, pode-se dizer que todas as empresas do segmento passam por situação parecida como a identificada no caso da Eletrosul, embora em algumas a expressividade do fato se dê em menor grau de representatividade e, em outras, talvez, em um grau um pouco mais substancial. $\mathrm{O}$ mencionado fato gerador de custos invisíveis trata-se da renovação do quadro de pessoal de tais organizações, dada em função da busca pela aposentadoria de parcela expressiva deste quadro. 
Gestão estratégica dos custos invisíveis: o caso das empresas estatais transmissoras de energia elétrica do Brasil

Marcelo Dutra, Antônio Cezar Bornia

A problemática surge em razão dos empregados que estão se desligando das empresas, em geral empregados com larga experiência, estarem sendo substituídos por profissionais que recentemente entraram no mercado de trabalho, sendo parcela substancial destes representada por pessoas que não possuem nenhuma experiência técnico-profissional na área, a não ser a formação acadêmica, que em determinados casos não dá o alicerce esperado pela empresa para desenvolver atividades relativamente complexas e com inúmeras especificidades.

Este fator, ao que demonstram as respostas dos questionários, é resultado da exigibilidade de concurso público para a admissão aos cargos, sem considerar aspectos de experiência profissional na área técnica. Tais respostas dão a entender, também, que o maior agravamento desta situação surgiu em função de muitos anos seguidos sem concurso público para a contratação efetiva de novos empregados, de tal modo que contratados temporários vinham absorvendo as atividades, funções e conhecimentos derivados da prática profissional.

Dessa forma, o fato de não ter ocorrido transição de conhecimentos, ou seja, devido a esta situação imposta por problemas de natureza burocrática, com poucas exceções, resultou na não existência de uma geração intermediária de empregados efetivos, o que afetou a continuidade e manutenção da expertise e do know-how, adquiridos pelo tempo e experiência dos profissionais, dado pelo tempo e espaço da empresa no mercado. Em outras palavras, o grande risco envolvido é a perda da memória organizacional.

\section{O CASO ELETROSUL}

Uma das maiores empresas estatais transmissoras de energia elétrica do Brasil é a Eletrosul Centrais Elétricas S.A., ou simplesmente Eletrosul, com aproximadamente 1.500 empregados (colaboradores). Essa companhia identificou um custo invisível em seu quadro de pessoal, cujo fator gerador poderia resultar em excessivos gastos futuros, inclusive com treinamento e consultoria (sem falar em outras questões ligadas à qualidade e know-how técnico), em virtude da evasão de conhecimento que se dará em função da saída em massa dos empregados denominados aposentáveis (de acordo 
Gestão estratégica dos custos invisíveis: o caso das empresas estatais transmissoras de energia
elétrica do Brasil
Marcelo Dutra, Antônio Cezar Bornia

com as regras da Previdência Social e também da Fundação de Previdência Complementar da própria Eletrosul).

Esses empregados foram assim considerados por terem condições de se aposentar num período de tempo inferior a cinco anos, podendo deixar a empresa sem permitir a sua substituição em tempo hábil, de maneira a evadir com eles seus conhecimentos adquiridos pela vivência e experiência no setor, e seus conhecimentos para o cumprimento de suas funções ou das execuções de suas atividades (memória organizacional da empresa), cruciais para o adequado funcionamento da entidade.

A posição da empresa, diante de tal situação, foi a seguinte (ELETROSUL, 2005, p. 02 e 03):

A Eletrosul, por ser uma empresa que presta, sob concessão, um serviço público de caráter ininterrupto e que exige qualidade e confiabilidade rítmicas sob condições contratuais que se não satisfeitas podem implicar irreparáveis danos à sociedade além de pesadas multas à empresa, há que dispor de mecanismos eficazes e permanentes para gerenciar e manter um quadro de empregados quantitativo e qualitativo condizente com tais características e responsabilidades.

(...)

Os novos empregados antes de assumirem as atividades dos empregados desligados necessitam de forte e longo treinamento, grande parte do tempo in loco. Assim, os empregados remanescentes, além das suas funções normais, suprem a falta do colega desligado e ainda têm que se dedicar ao treinamento dos novos. Esta situação deixa a empresa refém da necessidade de absoluta normalidade no sistema elétrico e vulnerável, portanto, a qualquer falha ou incidente elétrico, o que não é compatível com os níveis de qualidade e de confiabilidade exigidos na prestação do serviço público de energia elétrica.

$(\ldots)$

No intuito de salvaguardar a sua massa crítica de empregados treinados e com experiência, necessários ao cumprimento da sua Missão, e para poder admitir, treinar, planejar e programar a sua adequada reposição num programa de sucessão ajustado ao cronograma de desligamento por motivo de aposentadoria, a Eletrosul implantou, na condição de instrumento permanente 
Gestão estratégica dos custos invisíveis: o caso das empresas estatais transmissoras de energia elétrica do Brasil

Marcelo Dutra, Antônio Cezar Bornia

de recursos humanos, um plano para a aposentadoria programada de seus empregados.

(...)

O Programa de Readequação Programada do Quadro de Lotação (PREQ) tem por objetivo principal manter e disseminar internamente os conhecimentos imprescindíveis ao pleno cumprimento da Missão da Eletrosul, ao mesmo tempo que dinamizará seu quadro de pessoal permitindo o acesso de novos empregados em face da programação dos desligamentos por aposentadoria daqueles que já se encontram nesta situação. Manter a expertise necessária à gestão dos negócios não significa "reter" os que a detém até o ocaso das suas produtividades, mas sim fazer com que cada empregado repassem-na àquele que o substituirá nas suas atividades. Para tanto, a cronologia dos desligamentos será definida pela Eletrosul conjugada com um Programa de Repasse de Conhecimentos (PRC).

O sentido maior da instituição do programa designado de PREQ é, portanto, constituir-se em uma estratégia de gestão de recursos humanos, uma ferramenta utilizada para preservar e exponencializar o conhecimento; a técnica do saber o "por quê", o "como", o "quando" e o "com quantos" se faz ou deveria ser feito determinado processo ou procedimento no âmbito da Eletrosul. O intuito deste mecanismo de gestão é programar a sucessão quantitativa (número de empregados) e qualitativa (conhecimentos) dos empregados que pretendem desligar-se do seu quadro de pessoal (ELETROSUL, 2005).

Para tal, o PREQ foi composto de três (sub) programas, cada qual com sua função específica:

- Programa de Repasse de Conhecimentos (PRC) - visa a possibilitar a retenção, aumento e disseminação dos conhecimentos inerentes aos negócios da empresa. Prevê o repasse do conhecimento, da função, da atividade e/ou das tarefas executadas pelo empregado que está se desligando da empresa;

- Programa de Preparação para a Aposentadoria (PPA) - visa a proporcionar aos empregados inscritos no PREQ, bem como aos seus respectivos cônjuges, informações a respeito desta nova fase da vida, contemplando 
Gestão estratégica dos custos invisíveis: o caso das empresas estatais transmissoras de energia elétrica do Brasil

Marcelo Dutra, Antônio Cezar Bornia

aspectos sociais, previdenciários, financeiros, de saúde, entre outros, considerados necessários para que essa transição ocorra da forma mais natural possível;

- Programa de Bônus para o Desligamento Voluntário por Cumprimento de Metas (PCM) - visa a habilitar o empregado a receber um bônus (uma remuneração por verbas rescisórias e por dedicação à empresa) ao assinar o seu desligamento voluntário da empresa. Essa parte do plano é a forma com que a empresa vincula o empregado a cumprir as demais etapas do PREQ que a ela interessam. O mais interessante nessa fase do plano é que a empresa, através de seus cálculos, afirma que a diferença salarial existente entre os empregados que estão saindo (no topo da carreira no Plano de Carreira, Cargos e Salários) e os novos (que iniciam nos patamares mais inferiores do Plano de Carreira, Cargos e Salários) permitirá à empresa realizar essa bonificação sem que tenha que realizar gastos adicionais, à margem do que já havia sido previsto sem a saída desses profissionais. A grande oscilação a ser gerenciada é o problema em termos de fluxo de caixa, posto que as substituições são dadas em ordem cronológica (o efeito moeda no tempo).

Em síntese, no contexto do PREQ, a cronologia dos desligamentos é definida exclusivamente pela empresa e deverá atender às necessidades de repasse de conhecimento e de preenchimento da vaga (PRC), bem como à preparação psicológica e social (responsabilidade corporativa da organização) dos empregados e dos respectivos cônjuges para a aposentadoria (PPA). A partir do cumprimento das metas preceituadas no programa, o empregado passa a fazer jus a um bônus financeiro para o seu desligamento voluntário (PCM). 
Gestão estratégica dos custos invisíveis: o caso das empresas estatais transmissoras de energia elétrica do Brasil Marcelo Dutra, Antônio Cezar Bornia

\section{CONSTRUCTO TEÓRICO}

\subsection{A Reestruturação do setor elétrico e a atividade de transmissão}

O setor elétrico brasileiro organizou-se empresarialmente a partir da década de sessenta, com a criação da Eletrobrás. Fundamentado no ideal de que o estado deveria fornecer a infra-estrutura adequada para o desenvolvimento econômico, o segmento foi constituído por empresas estatais federais e estaduais. Foram aproximadamente vinte anos de intensos e expressivos investimentos em energia elétrica (CUNHA; BORENSTEIN, 1999).

A partir do final da década de setenta, até meados da década de noventa, o setor elétrico nacional sofreu uma brutal desaceleração em termos de crescimento, em virtude do alto grau de endividamento de suas empresas e de problemas de tarifa de energia por conta do combate à inflação, não obstante, também, aos agravamentos da década de oitenta, criados principalmente pela interferência política na administração das empresas estatais, que levou a discussões sobre o papel do Estado na regulamentação da atividade econômica (CATAPAN, 2005).

Mais tarde, durante o governo Fernando Henrique Cardoso, o setor atravessou uma fase de mudanças em seu arcabouço institucional. Essas mudanças resultaram na redução da presença empresarial do Governo na economia deste mercado, de modo a estimular a competição em atividades até então monopolizadas por empresas estatais, com a conseqüente reestruturação do setor. Com esta reestruturação buscou-se apontar soluções para a crise que vinha se agravando desde o final da década de setenta e que, entre outras coisas, produziu o esgotamento da capacidade de investimentos das empresas estatais (GREGÓRIO, 2000).

A reestruturação foi sustentada na venda das concessionárias federais e estaduais de energia elétrica, mediante a segregação das empresas em Geradoras, Transmissoras e Distribuidoras. Iniciada com a venda da companhia ESCELSA Espírito Santo Centrais Elétricas S.A., em 1995 (a maioria das companhias foram vendidas entre 1997 e 1998), a privatização atingiu as geradoras e as distribuidoras, 
Gestão estratégica dos custos invisíveis: o caso das empresas estatais transmissoras de energia elétrica do Brasil

Marcelo Dutra, Antônio Cezar Bornia

deixando para o Estado a exclusividade na atividade de transmissão (CACHAPUZ, 2006).

Com essa concepção estratégica, a transmissão de energia passou a ser compreendida como um sistema responsável pela transferência de grandes blocos de energia das centrais geradoras aos centros de consumo; fato esse que the permitiu atuar como atividade setorial independente (PINTO, 2001).

Como um dos principais objetivos iniciais da privatização foi de criar a livre concorrência no setor, as transmissoras passaram a garantir o livre acesso para sustentar essa competitividade na geração e na distribuição (comercialização), permanecendo, naquele momento, estrategicamente, como estatais. Todavia, há que se destacar que novas regulamentações permitiram, mais adiante, a inserção de empresas privadas na atividade de transmissão (ROCHA, 2001).

Nesse contexto, atualmente a atividade de transmissão pode ser desmembrada em duas categorias. Na primeira categoria figuram as empresas de caráter predominantemente estatal, ou seja, as empresas de energia com antigos ativos (remuneradas principalmente pelo custo/investimento - via contrato de concessão). $\mathrm{Na}$ segunda, as empresas de energia com novos ativos (remuneradas pelo preço - via leilão), constituindo-se, principalmente, em empresas privadas e sociedades de propósito específico, envolvendo parcerias público-privadas (LAUER, 2006).

Segundo Lima e Padilha-Feltrin (2005), o segmento de transmissão de energia elétrica está passando por significativa mudança em seu ambiente econômico. Há aproximadamente uma década atrás o total de empresas que exploravam esta atividade era inferior a uma dezena. De acordo com os dados divulgados pelo ONS (2008) e também com base na Resolução Homologatória ANEEL № 670/08, o cenário nacional, em termos de transmissão de energia elétrica, apresenta atualmente algo em torno de quarenta corporações explorando diretamente a atividade, das quais menos de 1/4 (um quarto) são estatais ou subsidiárias de estatais. Muito embora em menor número, as estatais tornam-se muito mais expressivas que as privadas, quando o assunto em pauta são as cifras, tanto em termos de resultados quanto em termos patrimoniais. Mais de $90 \%$ das receitas do serviço de transmissão e, também, mais de 
Gestão estratégica dos custos invisíveis: o caso das empresas estatais transmissoras de energia elétrica do Brasil

Marcelo Dutra, Antônio Cezar Bornia

90\% do Sistema Integrado Nacional - SIN de transmissão de energia estão sob o comando das empresas estatais.

A Figura 1 coloca em destaque o relacionamento econômico das transmissoras com os agentes do setor elétrico (em 2003, o Mercado Atacadista de Energia - MAE foi substituído pela Câmara de Comercialização de Energia Elétrica - CCEE).

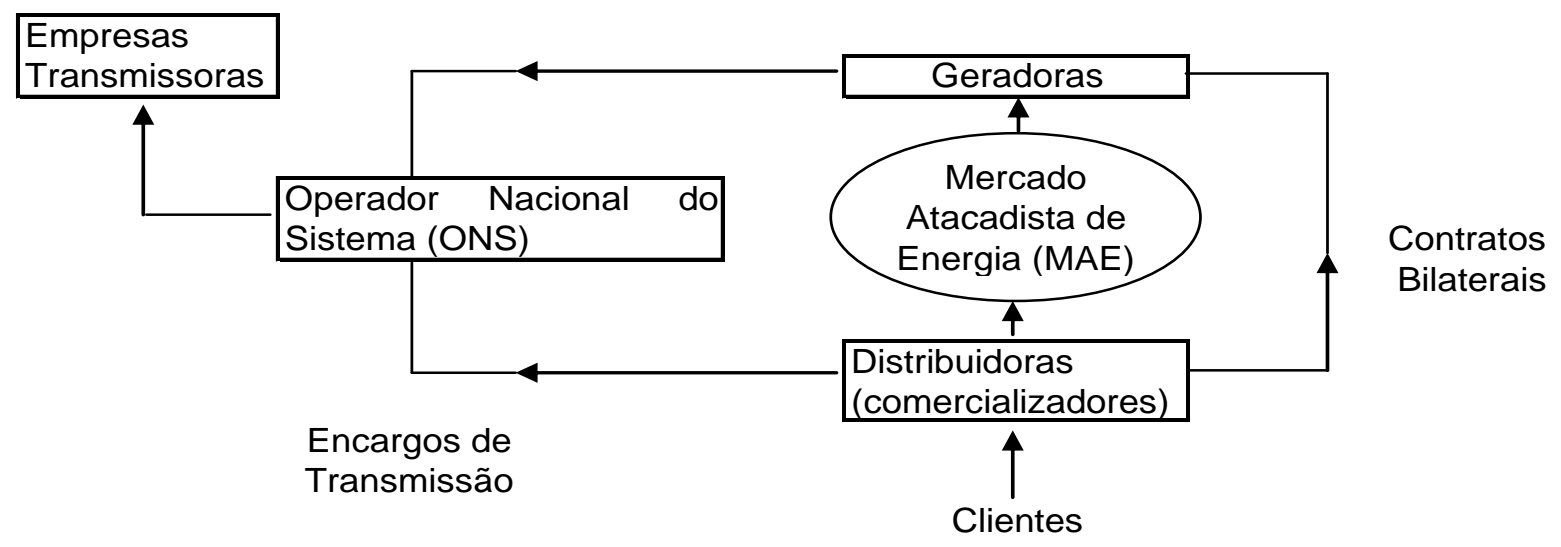

Figura 1 - Relacionamento entre os agentes do setor elétrico brasileiro Fonte: Adaptada de Coopers \& Lybrand (apud PINTO, 2001, p. 39)

Para sintetizar, pode-se dizer que a transmissão de energia passou a ser remunerada pela disponibilidade dos seus ativos, seja pelo uso da rede (encargos de uso) ou pela conexão (encargos de conexão), cabendo ao Operador Nacional do Sistema (ONS) a "negociação" deste serviço, e à ANEEL a determinação da Receita Anual Permitida RAP, a qual só pode ser modificada por intermédio de revisão (estudo técnico) sobre a tarifa.

\subsection{Transmissoras estatais e a problemática da gestão econômica}

Neste tipo de empresa as receitas principais são advindas de uma remuneração pré-estabelecida dada em função da sua capacidade de disponibilizar energia. Esta fonte de recursos é resultante de contrato firmado em razão da receita de transmissão, a qual, geralmente, dá origem, também, às mais expressivas receitas financeiras desse tipo de organização, sobretudo por força das cláusulas que embutem índices de atualização monetária, ou mesmo por valores estabelecidos em moedas estrangeiras. A 
resultante de tal característica é que poucas acabam sendo as possibilidades de aumentar, significativamente, por medida unilateral, as suas receitas, tendendo, quando das designadas revisões tarifárias, a reduzir a RAP (ANDRADE, 1998).

Com efeito, às transmissoras estatais resta como alternativa para a maximização de seus resultados a gestão (controle/redução) dos seus gastos, divididos em nãogerenciáveis e gerenciáveis. No primeiro grupo, o próprio nome já define a sua característica, que é a de que não possui possibilidades de gerenciamento. No caso do segundo grupo, embora intitulado como "gastos gerenciáveis", há que se considerar que a lei de licitações e a adequação a um orçamento definido no âmbito externo às empresas (orçamento vinculado à União), são fatores que restringem um possível gerenciamento direcionado à busca da eficiência de uma gestão pró-ativa de resultados positivos.

A esse respeito, Gambarotta (1989 apud LIMA, 1998) lembra que os principais elementos de pressão sobre os gastos públicos são: a necessidade constante de desenvolvimento econômico, o esforço para manutenção inercial da estrutura de gastos e uma restrição orçamentária fixada exogenamente - função exercida pelo Departamento de Coordenação e Controle das Empresas Estatais (DEST/MP), subordinado ao Ministério do Planejamento, Orçamento e Gestão (MP).

Lima (1998), por sua vez, afirma que, no intuito de controlar o desempenho das empresas estatais, o Governo acaba tirando a flexibilidade e a autonomia dos seus gestores, por intermédio da imposição de metas fiscais e de gastos, a ponto de comprometer sua capacidade de adaptação às várias transformações econômicas, sociais e políticas que caracterizam a realidade contemporânea. Em muitos casos os gestores desse tipo de empresa acabam engessados quando têm a finalidade de promover o melhor resultado econômico.

Diante deste contexto, admitindo-se que a performance do resultado econômico possa ser medida pela relação receitas/despesas e que a sua melhora está geralmente voltada ao controle/redução das despesas (e dos gastos em gerais) e para o aumento das receitas, torna-se possível verificar que, quando se trata de transmissoras estatais, é verdadeiramente complexo promover a maximização dos resultados, sobretudo em 
Gestão estratégica dos custos invisíveis: o caso das empresas estatais transmissoras de energia elétrica do Brasil

Marcelo Dutra, Antônio Cezar Bornia

razão do modelo atualmente adotado no setor para esse tipo de entidade e da forte burocracia que a envolve, enquanto estatal.

\subsection{Custos invisíveis sob o foco da gestão estratégica de custos}

A expressão 'gestão estratégica de custos', segundo Martins (2003, p. 297), "vem sendo utilizada nos últimos tempos para designar a integração que deve haver entre o processo de gestão de custos e o processo de gestão da empresa como um todo". De acordo com Shank e Govindarajan (1997), a designada gestão estratégica de custos surgiu da combinação de três temas vinculados à gestão estratégica das empresas, sendo eles: i) análise da cadeia de valor; ii) análise do posicionamento estratégico; iii) análise dos direcionadores de custos.

A cadeia de valor compreende o conjunto de atividades criadoras de valor para essa entidade, desde a fase inicial até o produto final. O posicionamento estratégico é a forma pela qual a empresa pretende competir - pelo menor custo ou pela diferenciação de produto ou serviço. No caso da análise dos direcionadores de custos, simplesmente a determinação e a alocação racional dos custos não mais são suficientes, pois isso já tem sido feito pelos tradicionais sistemas de custos; em consonância com os princípios dessa abordagem, torna-se preciso entender que os custos são causados por diversos fatores, e nem sempre esses fatores podem ser mensurados monetariamente (SHANK; GOVINDARAJAN, 1997).

Reside, portanto, justamente nesse sentido de integração da análise tradicional de custos com a gestão estratégica maior das entidades, as contribuições que podem se apresentar por meio da designada gestão estratégica de custos. A adoção desta concepção implica na utilização de uma abordagem que visa à melhoria contínua de desempenho, tornando-se, pois, de maior relevância para a tomada de decisão, em relação às abordagens tradicionais das análises de custos (MAHER, 2001).

Bernardi (2004, p. 265) afirma que, caso não seja possível mensurar os custos invisíveis que poderão advir, "a empresa ao menos deve ter consciência de sua existência, das causas e dos sintomas, e combatê-los, uma vez que minam sua saúde e a eficiência da gestão". Nesse mesmo sentido, Motomura (1999) pondera que não se 
deve avaliar os efeitos isolados de cada sinal (fatores) de custos invisíveis existentes, pois isoladamente podem ser de pequena importância e significância em relação ao total dos gastos de uma entidade, mas no conjunto podem se mostrar representativos. Portanto, sob a ótica de gestão estratégica é recomendável que os custos invisíveis sejam identificados, ordenados e avaliados, individual e conjuntamente, verificando-se se há necessidade efetiva de gerenciamento sobre eles.

Desse modo, na busca de não apenas determiná-los monetariamente, mas também considerá-los em toda a extensão em que possam surgir, seja no presente ou mesmo futuramente, é fundamental a compreensão do comportamento dos custos. A gestão estratégica dos custos invisíveis apresenta-se, destarte, como uma técnica que propõe a identificação e atuação preventiva sobre os fatores que originam esses custos, antes que eles produzam efeitos negativos e expressivos ao resultado do exercício das entidades. Prover os gestores com tais informações antecipadamente à sua ocorrência é fundamental nesses casos em que, muitas vezes, nem mesmo a mais eficiente auditoria consegue detectar onde surgiram determinados custos que insistem em alterar os efeitos das decisões tomadas (MEYERS; DURFEE, 2006).

Ao adotar esta percepção, passa-se a exigir dos profissionais responsáveis pela gestão das organizações não apenas decisões sobre questões programadas, advindas de situações rotineiras e repetitivas de sua área de atuação, mas também uma atuação estratégica, auxiliando no planejamento, controle e gestão da empresa, como um todo, de maneira pró-ativa, principalmente, em se tratando de empresas prestadoras de serviços em que, geralmente, o grande diferencial é a utilização do capital intelectual disponível, como é o caso das transmissoras estatais.

\subsection{Modelagem teórica (indutiva)}

A argumentação lógica e conceitual apresentada permite construir as seguintes assertivas: i) a gestão pró-ativa em busca dos resultados positivos das empresas estatais transmissoras do setor elétrico brasileiro é limitada pela segmentação deste mercado e pela forte burocracia que impera sobre as estatais; ii) a gestão estratégica dos custos invisíveis é uma técnica de gestão que proporciona diminuição de gastos e, 
Gestão estratégica dos custos invisíveis: o caso das empresas estatais transmissoras de energia elétrica do Brasil

Marcelo Dutra, Antônio Cezar Bornia

por conseqüência, aumento dos resultados econômico-financeiros, no médio e longo prazo.

Logo, pode-se inferir indutivamente que a adoção da gestão estratégica dos custos invisíveis pelas empresas estatais transmissoras do setor elétrico brasileiro, apresenta-se como uma possível alternativa para a maximização dos resultados econômicos destas organizações.

O objetivo da utilização da gestão estratégica dos custos invisíveis, nesse contexto, é focalizar a atenção dos gestores nos recursos restritos que poderão ser fatores inibidores do crescimento dos resultados futuros (no médio e longo prazo, principalmente). Note-se, todavia, que não se propõe, com isso, que as empresas estatais abandonem o seu foco principal, qual seja o de gerar resultados positivos voltados ao bem-estar social (retorno para a sociedade). O propósito é, sim, fortalecer a idéia de que, respeitando-se essa prioridade, o foco secundário passe a ser o melhor resultado econômico possível de se obter; até mesmo no sentido de melhor atender o foco principal - a demanda social.

Isto porque, conforme explicita Pinto (2001, p. 126), neste momento de transição de modelo, "talvez mais importante que aumentar a competitividade seja aumentar a eficiência (...) obtida, entre outras medidas, através da otimização das atividades (...), permitindo maximizar os resultados da organização".

\section{CONSIDERAÇÕES FINAIS}

A adoção de práticas organizacionais bem-sucedidas em outras entidades, desde que adequadamente absorvidas, podem conduzir as empresas ao desenvolvimento de uma cultura voltada ao aprendizado contínuo e ao processo criativo, que contribuem significativamente para a gestão das organizações. Nesse sentido, o presente trabalho apresentou a experiência vivida pela Eletrosul, desencadeada por uma mudança brusca e repentina no quadro de pessoal, em que se fez necessária a adoção de controles de gestão (bem como, de planejamento e acompanhamento) para atenuar futuros gastos que possam advir por conta desse 
processo. Acredita-se que, nesse sentido, a adoção da designada gestão estratégica dos custos invisíveis pode contribuir para a maximização dos resultados econômicos, no médio e longo prazo, das empresas estatais transmissoras de energia elétrica do Brasil.

A relevância desta abordagem está na percepção de que nem mesmo um excelente sistema de custos tem a capacidade de resolver o problema dos custos invisíveis das empresas. A solução para problemas dessa natureza pende de ações firmes e de avaliação e acompanhamento constantes, que possibilitem explicitar as perdas, a ociosidade, os desperdícios, os refugos e as ineficiências dos processos e atividades.

Os custos invisíveis quando não gerenciados, ou mal administrados, podem levar a efeitos negativamente devastadores ao patrimônio da entidade. Daí a eminente importância da gestão estratégica dos custos invisíveis, fundamentada na possibilidade de se gerirem custos controláveis que necessitam ser identificados e mapeados, para que os gestores tomem conhecimento de sua existência e possam realizar uma atuação incisiva sobre estes.

Cabe destacar que a gestão estratégica dos custos invisíveis pode servir também para outros tipos de organização, embora o direcionamento dado neste trabalho esteja voltado às transmissoras estatais, face à urgência de instrumentos e técnicas de gestão que melhorem os resultados deste tipo de entidade, usualmente engessadas em termos de flexibilização e/ou alternativas que promovam a melhoria do desempenho econômico.

A melhoria do desempenho econômico das transmissoras estatais permitirá atenuar três problemas existentes que cercam esse tipo de companhia: a necessidade de aporte de capital por parte do Governo; o apelo favorável à privatização fundado na ineficiência de gestão; e, a redução da empresa por necessidades financeiroeconômicas, culminada em descontinuidade parcial de sua atividade ou de seu serviço.

Não obstante, em última análise, reduzir os gastos nas empresas do setor elétrico pode significar redução da tarifa e, consequentemente, proporcionar uma menor conta de luz para os usuários, ou ainda gerar maiores resultados para que se possam 
Gestão estratégica dos custos invisíveis: o caso das empresas estatais transmissoras de energia elétrica do Brasil

Marcelo Dutra, Antônio Cezar Bornia

realizar maiores investimentos e, destarte, prestar um serviço mais adequado ao consumidor. Desse modo, alternativas que promovam um melhor desempenho dessas empresas são essenciais para a sociedade. Mais do que isso, pode-se tratar a questão como um ato de responsabilidade na gestão pública.

Neste tipo de empresa, predominantemente estatal, tão importante quanto qualquer técnica ou mecanismo de gestão eficiente é a vontade política de promover o bem-estar social, e não fazer uso dessas empresas como um mero instrumento de favorecimento político.

\section{REFERÊNCIAS}

ANDRADE, T.A. (1998). Aspectos distributivos na determinação de preços públicos. Rio de Janeiro: IPEA.

ANEEL - Agência Nacional de Energia Elétrica. Disponível em: http://www.aneel.gov.br. Acesso em: 20/abril/2008.

AS 500 MELHORES EMPRESAS DO BRASIL. (2008). Revista IstoÉ Dinheiro. Edição Especial, n. 567, ano 11, p. 132. Disponível em: http://www.terra.com.br/istoedinheiro/. Acesso em: 11/set/2008.

BERNARDI, L.A. (2003). Manual de empreendedorismo e gestão: fundamentos, estratégias e dinâmicas. São Paulo: Atlas.

. (2004). Manual de formação de preços: políticas, estratégias e fundamentos. (3. ed.). São Paulo: Atlas.

BRASIL. Resolução Homologatória ANEEL no 670, de 24 de junho de 2008. Estabelece as receitas anuais permitidas para as concessionárias de transmissão de energia elétrica, pela disponibilização das instalações de transmissão integrantes da Rede Básica e das demais instalações de transmissão, e dá outras providências. Disponível em: http://www.aneel.gov.br/cedoc/reh2008670.pdf. Acesso em: 20/ago/2008.

CACHAPUZ, P.B.B. (Coord.). (2006). Panorama do setor de energia elétrica no Brasil. Rio de Janeiro: CMEB (Centro da Memória da Eletricidade no Brasil).

CATAPAN, E.A. (2005). A privatização do setor elétrico brasileiro: os reflexos na rentabilidade e solvência das empresas distribuidoras de energia. 2005. 210f. (Tese de Doutorado). Programa de Pós-Graduação em Engenharia de Produção. UFSC, Florianópolis. 
Gestão estratégica dos custos invisíveis: o caso das empresas estatais transmissoras de energia elétrica do Brasil

Marcelo Dutra, Antônio Cezar Bornia

CUNHA, C.J.; BORENSTEIN, C.R. (1999). Mudança organizacional na Eletrosul: regulação e sistema de poder. Revista de Administração da USP. São Paulo, v. 34, n. 2, p. $81-90$.

ELETROSUL. (2005). Exposição de motivos: Plano de Readequação Programada do Quadro de Lotação (PREQ). Relatório enviado ao DEST/MP. Florianópolis.

FALCONER, K.; WHITBY, M. (1999). The invisible costs of scheme implementation and administration. In G. Van Huylenbroeck and M. Whitby (eds.). Countryside Stewardship: Farmers, Policies and Markets. Elsevier Science.

GIL, A.C. (1995). Como elaborar projetos de pesquisa. (3 ed.). São Paulo: Atlas.

GREGÓRIO, T.A. (2000). O custo de uma concessão e a privatização no setor elétrico brasileiro 80f. (Dissertação de Mestrado). Programa de Pós-Graduação em Engenharia de Produção. UFSC, Florianópolis.

HAMMOND, J.S.; KEENEY, R.L.; RAIFFA, H. (2006). Armadilhas ocultas na tomada de decisão. Harvard Business Review (Brasil). São Paulo, p. 84 - 92, Jan.

LAUER, O.C. (2006). Avaliação de empresas (Valuation): o fluxo de caixa descontado aplicado a empresas transmissoras de energia elétrica. 2006. 215f. (Dissertação de Mestrado). Centro de Ciências da Administração, UDESC, Florianópolis.

LIMA, D.A.; PADILHA-FELTRIN, A. (2005). Comparação de propostas para a alocação dos custos de perdas na Transmissão. Revista Controle \& Automação. São Paulo, v. 16, n. 1, fev./março.

LIMA, I.S. (1998). Contribuição ao estudo da eficácia na aplicação do contrato de gestão nas empresas estatais. (Tese de Doutorado). Curso de Pós-Graduação em Contabilidade. USP, São Paulo.

MAHER, M. (2001). Contabilidade de custos: criando valor para a administração. Tradução de José Evaristo dos Santos. São Paulo: Atlas.

MARTINS, E. (2003). Contabilidade de custos. (9 ed.). São Paulo: Atlas.

MEYERS, M.; DURFEE, A. (2006). Who pays? The visible and invisible costs of child care. Journal Politics \& Society. Thousand Oaks (CA/USA), v. 34, № 1, p. $109-128$.

MILLER, J.G.; VOLLMANN, T.E. (1985). The hidden factory. Harvard Business Review. Set/Out.

MOTOMURA, O. (1999). A gestão do invisível. Disponível em: www.perspectivas.com.br/leitura/17a.htm. Acesso em: 30/dez/2007. 
Gestão estratégica dos custos invisíveis: o caso das empresas estatais transmissoras de energia elétrica do Brasil

Marcelo Dutra, Antônio Cezar Bornia

ONS - Operador Nacional do Sistema Elétrico. Disponível em: http://www.ons.org.br. Acesso em: 30/junho/2008.

PINTO, M.S.L. (2001). A reestruturação e a privatização do setor elétrico brasileiro e os impactos sobre a transmissão de energia da CHESF na visão de seus Stakeholders. (Dissertação de Mestrado). Programa de Pós-Graduação em Administração. UFPE, Recife.

ROCHA, P.G. (2001). Preços ótimos para o sistema de transmissão: análise das abordagens de custo marginal, selo e regra de Ramsey - o caso do sistema de transmissão da CHESF. (Tese de Doutorado). Programa de Pós-Graduação em Economia. UFPE, Recife.

ROSA, C. (2004). Gestão estratégica escolar. Petrópolis: Vozes.

SCHLENDER, B. (2004). Peter Drucker sets us straight. Fortune. New York, no 149, p. 115, Jan.

SHANK, J.K.; GOVINDARAJAN, V. (1997). A revolução dos custos. (2 ed.). Rio de Janeiro: Campus.

SOUZA, P.R.C. (1995). Avaliação do planejamento estratégico: o caso da Eletrosul. 1995. 119f. (Dissertação de Mestrado). Programa de Pós-Graduação em Engenharia de Produção. UFSC, Florianópolis.

YIN, R.K. (2004). Estudo de caso: planejamento e métodos. (3 ed.). Porto Alegre: Artmed.

ZAFFANI, C.A. (2006). Cuidado com os custos invisíveis. Revista Boletim CRC/SP. São Paulo, № 158, p. 19 - 22, Mar/Maio.

Data de Submissão: 01/04/2009

Data de Aceite: 14/04/2009 